\title{
Estimativa do Potencial Natural de Erosão dos Solos da Bacia Hidrográfica do Alto Gurguéia, Piauí-Brasil, com uso de Sistema de Informação Geográfica
}

\author{
Estimation of the Natural Soil Erosion Potential of the Upper Gurguéia Basin, Piauí- \\ Brazil, using Geographic Information System
}

\author{
Reurysson Chagas de Sousa Morais \\ Doutorando em Desenvolvimento pela UFC, professor do \\ Instituto Federal de Educação, Ciência e Tecnologia do Piauí, Brasil \\ reurysson@ifpi.edu.br \\ Marta Celina Linhares Sales \\ Doutora em Geografia Física, professora do Programa de \\ Pós-Graduação em Geografia da UFC, Brasil \\ mclsales@uol.com.br
}

\begin{abstract}
Resumo
O objetivo deste trabalho é apresentar uma estimativa do Potencial Natural de Erosão (PNE) dos solos da bacia hidrográfica do alto Gurguéia (BHAG), Piauí, calculado por meio do produto dos parâmetros físicos da Equação Universal de Perda de Solo: erosividade das chuvas (fator R), fator topográfico (fator LS) e erodibilidade dos solos (fator K) apoiado com uso de Sistema de Informação Geográfica e dados de Sensoriamento Remoto. O fator R foi calculado utilizando dados de precipitação estimados por satélite, enquanto o fator LS foi obtido a partir do modelo digital de elevação Alos World 3D processado utilizando a ferramenta LS-TOOL. Já os valores do fator K foram calculados com base na composição granulométrica do horizonte A dos solos da bacia. Os resultados indicam que a BHAG apresenta baixo potencial natural de erosão, tendo em vista que $80 \%$ da área da bacia apresenta PNE $\leq 400$ t.ha $^{-1}$. ano ${ }^{-1}$, no entanto, nas áreas declivosas associadas às escarpas das bordas dos planaltos, chapadas e superfícies residuais, esses valores ultrapassam 1.600 t.ha ${ }^{-1} \cdot$ ano $^{-1}$ (6,4\% da área total) demostrando forte influência do fator topográfico na estimativa do PNE em detrimento aos demais parâmetros, comprovado por meio da análise de correlação entre PNE e os fatores R, K e LS. A identificação da topográfica como fator principal de desencadeamento de processos erosivos frente à condição de excessiva erosividade das chuvas na BHAG $\left(\mathrm{R}_{\text {média }}=6.297 \mathrm{Mj} \cdot \mathrm{mm} \cdot \mathrm{ha}^{-1} \cdot \mathrm{h}^{-1} \cdot \mathrm{ano}^{-1}\right)$ evidencia a alto risco de erosão a que estão submetidas as áreas da bacia que apresentam declividade acentuada, condição que demanda a adoção de planejamento ambiental com vista a disciplinar o uso e ocupação compatibilizado as categorias de uso às condições ambientais da bacia.
\end{abstract}

Palavras-chave: degradação dos solos, geoprocessamento, rio Gurguéia.

\begin{abstract}
The objective of this work is to present an estimate of the Natural Potential Erosion (NPE) of the soils of the upper Gurguéia basin, Piauí, calculated using the product of the physical parameters of the Universal Soil Loss Equation: rainfall erosivity factor R), topographic factor (LS factor) and soil erodibility (factor K) supported using Geographic Information System and Remote Sensing data. The $\mathrm{R}$ factor was calculated using estimated satellite precipitation data, while the LS factor was obtained from the Alos World 3D digital elevation model processed using the LS-TOOL tool. The K factor values were calculated based on the granulometric composition of the A horizon of the soils of the basin. The results indicate that the upper Gurguéia basin presents a low natural erosion potential, considering that $80 \%$ of the basin area presents NPE $\leq 400 \mathrm{t}^{-h a^{-1}} \cdot \mathrm{y}^{-1}$, however, in the sloping areas associated with the escarpments of the plateau borders, plateaus and residual surfaces, these values exceed 1,600 t.ha $^{-1} \cdot \mathrm{y}^{-1}$ (6.4\% of the total area), demonstrating a strong influence of the topographic factor in the estimation of NPE in detriment to the other parameters, as evidenced by the analysis of
\end{abstract}


correlation between NPE and R, K and LS factors. The identification of topography as the main triggering factor for erosive processes in the upper Gurguéia basin $\left(R_{\text {average }}=6,297 \mathrm{Mj} \cdot \mathrm{mm} \cdot \mathrm{ha}^{-1} \cdot \mathrm{h}^{-1} \cdot \mathrm{y}^{-}\right.$ $\left.{ }^{1}\right)$ shows a high risk of erosion are submitted to areas of the basin that show marked declivity, a condition that requires the adoption of environmental planning in order to discipline the use and occupation compatible the categories of use to the environmental conditions of the basin.

Keywords: soil degradation, geoprocessing, Gurguéia river.

\section{INTRODUÇÃO}

A erosão dos solos é considerada um dos mais importantes problemas ambientais da atualidade pois atinge indiscriminadamente regiões agrícolas, centros urbanos e áreas naturais. Segundo Lepsch (2010), as perdas de solos decorrente da erosão, especialmente em áreas agrícolas, representa um grande prejuízo ecológico e econômico. Para o autor a erosão acelerada decorrente da remoção e transporte das partículas do solo pelo vento e água, está entre as principais causas de depauperamento dos solos.

A erosão hídrica destaca-se entre os demais tipos de erosão pela sua alta capacidade de remoção e transporte de sedimento, podendo ocorrer de duas formas distintas: erosão laminar, caracterizada pela remoção de uma fina camada na parte superior do solo; e erosão linear, caracterizadas por incisões nos solos, que se expressam desde de pequenos sulcos (erosão em sulco) até a forma de voçorocas (BERTONI; LOMBARDI NETO, 2014; GUERRA, 2005a).

A erosão hídrica ocorre especialmente em áreas de clima tropical, devido as taxas mais elevadas de precipitação, quando comparadas as demais regiões da Terra. No entanto, em função do caráter sistêmico da erosão, alterações em algum dos condicionantes geoambientais (solo, declividade, vegetação, dentre outros) podem resultar no desencadeamento e avanço de processos erosivo nas mais diferentes regiões.

Salomão (2005) argumenta que a adoção de medidas preventivas e corretivas da erosão hídrica depende da compreensão dos processos dinâmicos decorrentes do impacto da água da chuva nos solos e do escoamento gerado. Assim sendo, o autor ressalta que os processos erosivos podem ser estudados seguindo duas abordagens distintas, a da quantificação das perdas de solo por erosão e a abordagem da avaliação qualitativa do comportamento erosivo sobre o terreno.

No escopo dessa abordagem quantitativa foram apresentadas ao longo do tempo diversas metodologias para estimar a perda de solo por erosão, sendo a Equação Universal de Perda de Solo (EUPS) (Equação 1), proposta por Wischmeier e Smith (1978), a mais difundida pois procura sintetizar a atuação dos principais fatores que são responsáveis pela erosão hídrica (BERTONI; LOMBARDI NETO, 2014). 


$$
A=R \cdot K \cdot L \cdot S \cdot C \cdot P
$$

Onde: $\mathrm{A}=$ perda de solo por unidade de área, em t.ha ${ }^{-1} \cdot \mathrm{ano}^{-1}$; $\mathrm{R}=$ fator de erosividade, em MJ.mm.ha' ${ }^{-1} \cdot \mathrm{h}^{-1} \cdot \mathrm{ano}^{-1} ; \mathrm{K}=$ fator de erodibilidade do solo, em t.ha.h.ha ${ }^{-1} \mathrm{MJ}^{-1} \cdot \mathrm{mm}^{-1} ; \mathrm{L}=\mathrm{Fator}$ comprimento da encosta (adimensional); $\mathrm{S}=$ fator de declividade; $\mathrm{C}=$ fator uso e manejo; $\mathrm{P}=$ fator de prática conservacionista.

A perda de solo estimada pela EUPS considera além de fatores naturais, aqueles decorrentes da intervenção antrópica como o tipo de manejo do solo e as práticas conservacionistas adotadas, o que a torna ideal para obtenção de estimativa de perdas de solos em áreas agrícolas. Sobre esse assunto Salomão (2005) argumenta que o cálculo da EUPS é mais preciso em pequenas áreas em virtude das variações espaciais dos parâmetros serem mais facilmente observadas. Segundo o autor, em estudos regionais de erosão - a exemplo de médias e grandes bacias hidrográficas - os valores de perdas de solo não podem ser tomados com dados reais de erosão, e sim utilizados para caracterizar qualitativamente as áreas quanto a sua maior ou menor susceptibilidade à erosão laminar.

Assim sendo, diversos pesquisadores têm utilizado o Potencial Natural de Erosão (PNE), definido a partir dos parâmetros físicos da EUPS (R, K e LS), para estimar as perdas de solos (CARVALHO et al., 2010; DEMARCHI, 2012; SILVA, 2008). Segundo Oliveira, F. et al. (2015), o PNE corresponde às perdas de solo em áreas continuamente destituídas de cobertura vegetal e sem qualquer intervenção antrópica. Diante do exposto, o presente trabalho tem como objetivo estimar o potencial natural de perdas de solo da bacia hidrográfica do Alto Gurguéia (BHAG) apoiado com uso de Sistema de Informação Geográfica e dados de Sensoriamento Remoto. Parte-se da hipótese de que a região apresenta o quadro natural bastante susceptível a ocorrência de processo erosivos, e que o conhecimento do PNE pode auxiliar no processo de gestão ambiental. Este trabalho representa, portanto, um esforço de compreensão da dinâmica ambiental da BHAG com vista ao desenvolvimento futuro de uma proposta de ordenamento territorial.

\section{LOCALIZAÇÃO DA ÁREA DE ESTUDOS}

A área selecionada para desenvolvimento deste estudo de caso foi a bacia hidrográfica do Alto Gurguéia (BHAG) localizada no sul do estado do Piauí, Brasil (Figura 1). Com aproximadamente $4.795 \mathrm{~km}^{2}$ de área, esta bacia abrange territórios de sete municípios (Redenção do Gurguéia, Bom Jesus, Gilbués, Monte Alegre do Piauí, São Gonçalo do Gurguéia, Riacho Frio e Corrente). A ocupação da BHAG é eminentemente rural, dentre as principais atividades econômicas destacam-se são a agricultura e pecuária de subsistência. 
A BHAG está parcialmente inserida no Núcleo de Desertificação de Gilbués, uma área ambientalmente frágil, conhecida pelo seu avançado estágio de degradação dos solos atribuído a condicionantes geoambientais e ação antrópica, notadamente desmatamento e mineração (CREPANI, 2009; SALES, 2003)

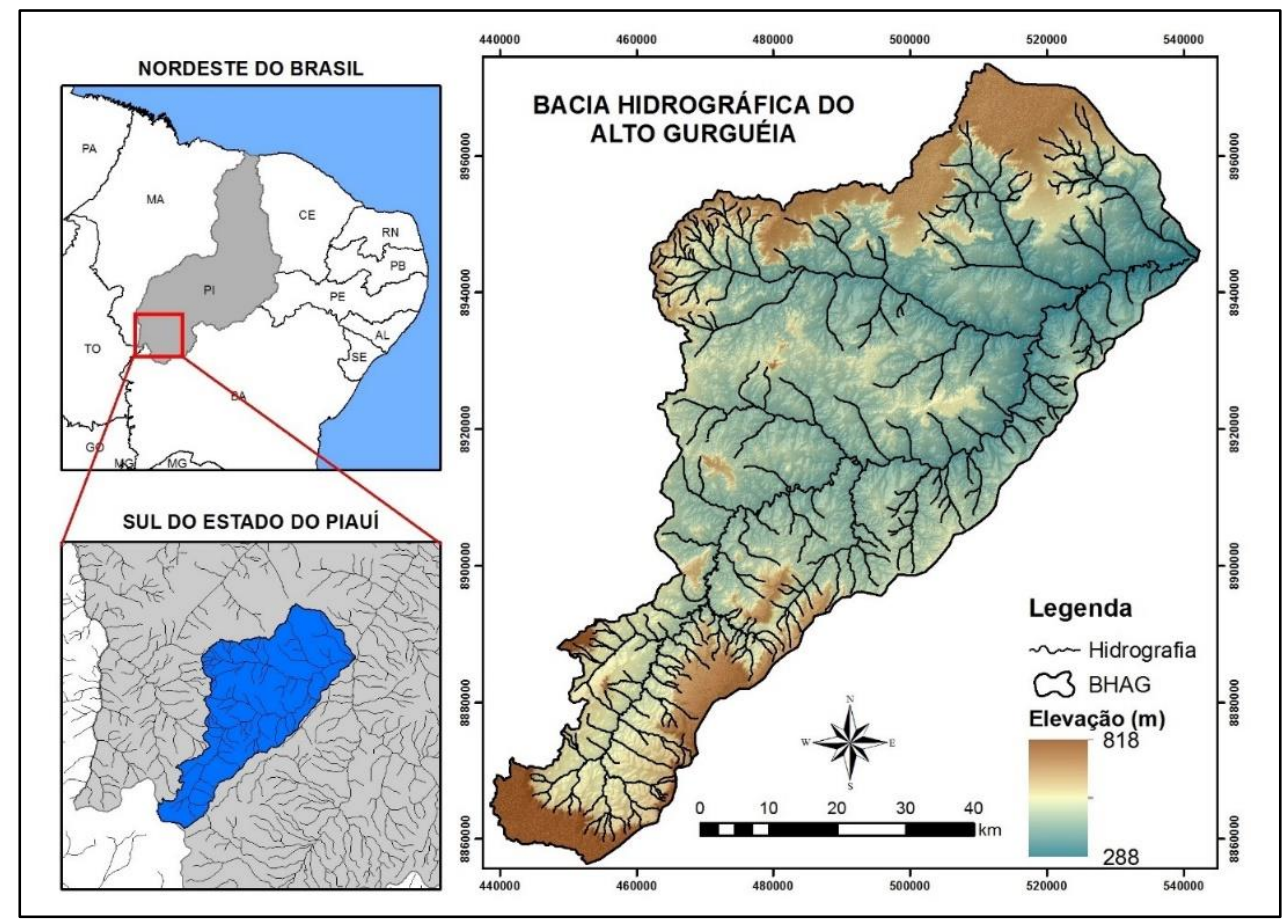

Figura 1- Localização da Bacia Hidrográfica do Alto Gurguéia (BHAG).

Fonte: elaborado pelos autores.

A base geológica da região é constituída exclusivamente por rochas sedimentares, com destaque para as formações Poti e Piauí, unidades litoestratigráficas pertencentes à bacia sedimentar do Parnaíba que abrange $70 \%$ da área da bacia. Ao Sul, sobreposto à esta bacia, ocorrem os arenitos das formações Urucuia e Areado, pertencentes à bacia sedimentar do São Francisco, cobrindo 27\% da área da bacia. Os depósitos aluvionares somados à ocorrência localizadas das formações Longá e Pedra de Fogo cobrem os 3\% restantes da área da bacia (GONÇALVES, 2006; LIMA; BRADÃO, 2010).

A região apresenta clima do tipo subúmido seco, segundo a classificação climática de Thornthwaite, com período chuvoso concentrado entre os meses de dezembro e abril, baixa amplitude térmica anual, precipitação e temperatura média anual da ordem de 1000 a $1200 \mathrm{~mm}$ e 24 a $26^{\circ} \mathrm{C}$, respectivamente (ANDRADE JUNIOR et al., 2004, 2005).

Na BHAG verifica-se a ocorrência de seguintes unidades de relevo (FERREIRA; DANTAS, 2010): 
- Superfícies Aplainadas Degradadas: são áreas situadas abaixo dos 500 metros de altitude que se estendem por toda a área de ocorrências das Formações Poti, Piauí, Areado e Urucuia, representando cerca de $74,2 \%$ da área da bacia. Nessas áreas a morfogênese acentuada resulta na ocorrência de processo erosivos intensos. Os solos são em geral pouco espessos e podem ser divididos em dois grupos: os que apresentam moderada a boa fertilidade natural (Luvissolos Crômicos, Argissolos Vermelhos eutróficos e Argissolos Vermelho-Amarelos eutróficos); e os solos de baixa fertilidade natural (Latossolos Amarelos distróficos, Neossolos Quartzarênicos e Argissolos Vermelho-Amarelos distróficos).

- Planaltos e Baixos Platôs: ocorrem em uma pequena área (14,6\% da área da bacia) situada no extremo norte da bacia e fazem parte dos planaltos do sudoeste piauiense onde ocorre larga produção de grãos no estado do Piauí. Encontram-se numa altitude inferior a 700 metros a apresentam solos do tipo Latossolos Amarelos distróficos, sobre os quais desenvolvem-se vegetação típica de Cerrado.

- Chapadas e Platôs: corresponde a uma extensão da Chapada das Mangabeiras situada no sul da bacia (7,8 \% de sua área), como altitudes acima dos 700 metros. Devido seu relevo plano, essas áreas são comumente utilizadas para a desenvolvimento de agricultura mecanizada, à exceção das áreas integrantes do Parque Nacional das Nascentes do Rio Parnaíba. No topo dessas estruturas predominam os Latossolos Amarelos distróficos também associados a uma vegetação do tipo Cerrado.

- Escarpas serranas: representam vertentes bastante íngremes e dissecadas por uma rede de canais que confere um aspecto festonado à escarpa, devido ao recuo erosivo diferencial. Essas escarpas estão orientadas para norte, em direção à Depressão Sertaneja no estado do Piauí. Nessas áreas predominam os Neossolos Litólicos.

- Planícies Fluviais: correspondem as áreas planas situadas às margens do rio Gurguéia, onde predominam os solos Neossolos Flúvicos eutróficos. São, portanto, áreas com boa fertilidade natural, comumente utilizada para prática de agricultura de pequena escala ou de subsistência.

\section{MATERIAL E MÉTODOS}

O Potencial Natural de Erosão dos Solos (PNE) da bacia hidrográfica do Alto Gurguéia, foi definido a partir dos parâmetros físicos da EUSP: erosividade, erodibilidade, comprimento de encosta e declividade, conforme apresentado por Accioly et al. (2010), expresso pela Equação 2:

PNE=R.K .LS

Onde: $\mathrm{PNE}=$ potencial natural de erosão dos solos $\left(\mathrm{t} \cdot \mathrm{ha}^{-1} \cdot \mathrm{ano}^{-1}\right) ; \mathrm{R}=$ fator erosividade da chuva (MJ.mm.ha' $\left.{ }^{-1} \cdot \mathrm{h}^{-1} \cdot \mathrm{ano}^{-1}\right) ; \mathrm{K}=$ fator erodibilidade dos solos (t.ha.h.ha ${ }^{-1} \mathrm{MJ}^{-1} \cdot \mathrm{mm}^{-1}$ ) e LS = fator topográfico (adimensional).

A erosividade da chuva (fator R) é um índice numérico que expressa a capacidade da chuva, esperada para uma dada localidade, de causar erosão em uma área sem proteção vegetal (BERTONI; 
LOMBARDI NETO, 2014). O valor de R é resultante da soma dos valores mensais dos Índice de Erosão (IE) obtido por meio da Equação 3:

$$
\mathrm{EI}=67,355\left(\mathrm{r}^{2} / \mathrm{P}\right)^{0,85}
$$

Onde: $\mathrm{EI}=$ média mensal do índice de erosão, em MJ.mm.ha ${ }^{-1} \cdot \mathrm{h}^{-1} ; \mathrm{r}=$ precipitação média mensal em milímetros e $\mathrm{P}$ = precipitação média anual em milímetros.

Devido a indisponibilidade de dados consistentes de precipitação para a região da BHAG, optou-se por utilizar dados de precipitação estimados por satélite disponibilizados pelo Goddard Earth Sciences Data And Information Services Center (GES DISC) da Agência Espacial Americana (NASA) por meio da plataforma on-line GIOVANNI, acrônimo para GES DISC Interactive Online Visualization And Analysis Infrastructure (https://giovanni.gsfc.nasa.gov/giovanni/), com base no trabalho desenvolvido por Passos et al. (2014).

A erodibilidade refere-se à capacidade de um determinado solo resistir a atuação de processos erosivos. Ela está relacionada tanto às propriedades físicas, especialmente textura, estrutura, permeabilidade e densidade, quanto às propriedades químicas, biológicas e mineralógicas dos solos (SALOMÃO, 2005).

Ao longo do tempo diversas metodologias foram sendo desenvolvidas para obtenção por meios indiretos do fator K, conforme destacado por (ARAÚJO; SALVIANO; HOLANDA NETO, 2011; BERTONI; LOMBARDI NETO, 2014). Neste trabalho, optou-se por utilizar a proposta metodológica apresenta por (DENARDIN, 1990) (Equação 5).

$$
\mathrm{K}=(0,00000748 * \mathrm{M})+(0,004480 * \mathrm{P})-(0,0631175 * \mathrm{DMP})+(0,01039567 * \mathrm{R})
$$

Onde: $\mathrm{K}=$ é a erodibilidade dos solos, expresso em t.ha.h.ha ${ }^{-1} \cdot \mathrm{MJ}^{-1} \cdot \mathrm{mm}^{-1} ; \mathrm{M}=($ Areia fina + Silte $) *(($ Areia fina + Silte $)+$ Areia grossa $)$, em porcentagem; $\mathrm{P}=$ permeabilidade do solo, definida com base na descrição geral do perfil, codificada como: 1 = Muito Baixa, 2 = Baixa, 3 = Moderada, 4 = Alta e 5 = Muito Alta; R = (Areia grossa. (Teor de Matéria Orgânica/100), em porcentagem; DMP = é o diâmetro médio das partículas do solo definido pela Equação 6. Valores de areia, silte e argila expressos em porcentagem.

$\mathrm{DMP}=((0,62 *$ Areia grossa $)+(0,15 *$ Areia fina $)+(0,0117 *$ silte $)+(0,00024 *$ Argila $)) / 100$ (Eq. 6)

A base cartográfica vetorial dos solos, no formato shapefile, foi obtida na página eletrônica do Instituto Brasileiro de Geografia e Estatística, na escala original de 1:250000 (IBGE, 2015). Junto 
a esta base de dados são disponibilizados ainda os arquivos vetoriais de localização dos perfis de solo e o banco de dados contento a descrição dos horizontes dos perfis e composição granulométrica, bem como diversas outros parâmetros físico-químicos. Neste trabalho foi utilizado os arquivos correspondentes a folha SC-23, do mapeamento sistemático brasileiro.

Após a identificação das classes de solos que ocorrem na BHAG buscou-se localizar os perfis associados a cada classe, para consulta da composição granulométrica do horizonte A utilizado como referência para a definição do fator $\mathrm{K}$. Na ausência de perfis associados às classes de solos na área da bacia, tomou-se com referência aqueles localizados no entorno.

No intuito de adensar a base de dados e melhorar a estimativa do fator $\mathrm{k}$, a base de dados do IBGE foi complementada com as informações dos perfis de solo constantes no Levantamento Exploratório-Reconhecimento dos solos do Piauí (JACOMINE, 1986).

Na EUPS a influência da topografia nas taxas de erosão é analisada por meio do fator topográfico (fator LS), onde L é o comprimento da rampa medido em metros e S é o ângulo ou o índice da inclinação do terreno expresso em porcentagem. O fator LS representa, portanto, a "relação esperada de perdas de solo por unidade de área em um declive qualquer em relação as perdas de solo correspondentes a uma parcela unitária de $25 \mathrm{~m}$ de comprimento com 9\% de declive" (BERTONI; LOMBARDI NETO, 2014. p. 259).

Galdino (2015) destaca que a EUPS, em sua concepção original, deve ser aplicada somente pra encostas curtas o que dificulta a definição do fator LS para áreas de relevo mais complexo como bacias hidrográficas. No entanto, o desenvolvimento de metodologias apoiado no uso de SIG e Modelos Digitais de Elevação (MDE) tem permitido a obtenção do fator LS nestas unidades ambientais.

Sobre esse tema, Farinasso et al. (2006) argumentam que o comprimento de encosta é o parâmetro que possui maior dificuldade para ser obtido em ambiente computacional. Segundo os autores, o conceito área de contribuição, obtido a partir de um MDE, trouxe uma nova abordagem para a estimativa do comprimento das encostas. Assim, o fator LS passou a ser facilmente obtido a partir de MDE processado em ambiente SIG (GUIMARÃES et al., 2011; GALDINO, 2015).

Neste trabalho, o fator LS foi obtido com uso da ferramenta computacional LS-TOOL, desenvolvido por ZHANG et al. (2013), implementada no software GISus-M (OLIVEIRA et al, 2015) para permitir a leitura de MDE no formato de imagem. A tela com as configurações utilizadas para a obtenção do fator LS por meio desta ferramenta é apresentada na Figura 2. 


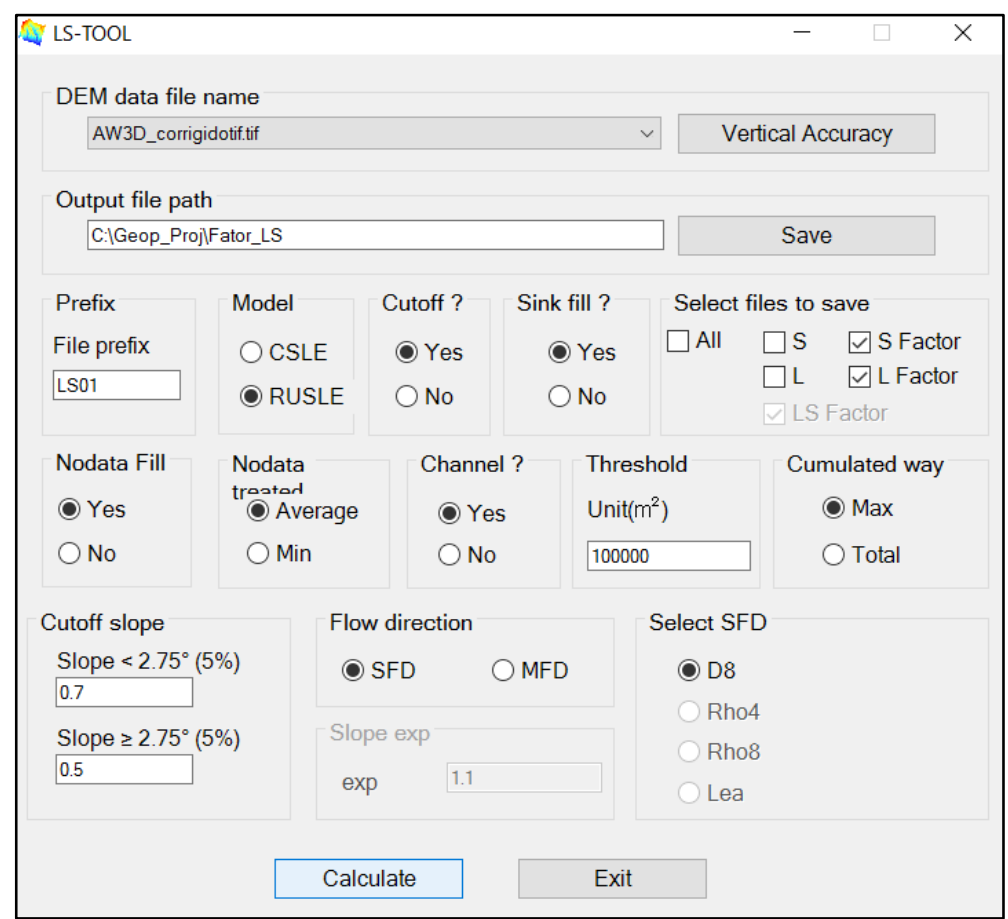

Figura 2 - Imagem da tela do LS-TOOL mostrando as configurações utilizadas na obtenção do fator LS Fonte: print screen da tela do LS-TOOLS no sistema operacional Windows 10.

Na estimativa do fator LS foi utilizado os dados de elevação ALOS WORD 3D (AW3D). Trata-se de um conjunto de dados de elevação, com aproximadamente $30 \mathrm{~m}$ de resolução espacial e cinco metros de precisão altimétrica o que o torna o conjunto de dados de elevação mais preciso se comparado aos demais de distribuição gratuita: Shuttle Radar Topography Mission (SRTM) e ASTER Global Digital Elevation Model (TAKAKU et al., 2014). Os dados utilizados neste trabalho estão disponíveis na página eletrônica da Agência de Exploração Espacial Japonesa (JAXA, 2016).

\section{RESULTADOS E DISCUSSÃO}

\subsection{Fator $\mathbf{R}$}

A chuva é um dos principais fatores que influenciam na erosão dos solos. Sua ação erosiva ocorre inicialmente pelo impacto das gotas no solo, que destaca as partículas disponibilizando-as para serem carreadas pelo escoamento superficial. Fatores como volume, intensidade, duração e frequência das chuvas estão diretamente relacionados como seu potencial erosivo (GUERRA, 2005b). Métodos de estimação da erosividade, como o proposto por Lombardi Neto e Moldenhauer (1992), são facilmente aplicáveis, visto que requer apenas os valores de precipitação média mensal e precipitação média anual, e tem boa aceitação na academia.

Os dados de precipitação utilizados foram estimados por meio de múltiplos sensores a bordo de diferentes plataformas orbitais, tais como a Tropical Rainfall Measuring Mission (TRMM), que 
se manteve operacional no período de 1997 a 2015, e sua sucessora, a missão Global Precipitation Measurement (GPM), operacional de 2014 até o presente, ambas uma parceria da NASA com a Agência de Exploração Espacial Japonesa (JAXA).

Foram utilizados os dados TRMM_3B43, versão 7, que disponibiliza os valores acumulados mensais de precipitação em milímetros (mm). O algoritmo 3B43 utilizado na produção desses dados combina estimativa de precipitação obtidas através de sensores micro-ondas de alta qualidade e infravermelho. Disso resulta a melhor estimativa de precipitação (em $\mathrm{mm} / \mathrm{h}$ ) em uma faixa de latitude de $50^{\circ} \mathrm{N}$ a $50^{\circ} \mathrm{S}$ (TRMM, 2011). Ressalta-se que a escolha dessa base de dados em detrimento às convencionais deve-se a baixa densidade de estações terrestres na área da bacia (apenas duas) e as excessivas falhas verificadas durante a fase de seleção e montagem da base de dados desse estudo.

Após a obtenção da base de dados selecionou-se uma área que envolvesse os limites da bacia para obtenção das taxas de precipitação acumulada mensal para o período de 01/01/1998 a 31/12/2016, no formato Network Common Data Form (NetCDF), e posterior importação dos mesmo para o programa ArcGis, versão 10.3, onde foram convertidos em imagens. A escolha desse intervalo temporal se deu em função da disponibilidade de dados.

A preparação do banco de dados em ambiente de Sistema de Informação Geográfica (SIG) demandou a criação de uma malha de pontos, no formato shapefile (.shp), com espaçamento compatível com a resolução espacial da base de dados que é de $0,25^{\circ}$ x $0,25^{\circ}(27,7$ x $27,7 \mathrm{~km})$, que resultou num total de 42 pontos que passaram a constituir as estações virtuais de análise climática da BHAG, conforme demonstrado na Figura 3.

Os valores mensais de precipitação para o período de janeiro de 1998 a dezembro de 2016 foram inseridos na tabela de atributos das estações virtuais como uso da ferramenta Extract Multi Values to Point do ArcGis. Posteriormente, procedeu-se ao cálculo e interpolação precipitação média anual e fator R utilizando o método de krigagem universal com uso da extensão Geoestatistical Analyst do ArcGis, seguindo o procedimento padrão da análise geoestatística: verificação da normalidade dos dados, análise de tendência, modelagem do semivariograma e análise do erro (YAMAMOTO; LANDIM, 2013).

A análise da distribuição espacial da precipitação média anual da BHAG (Figura 4) permitiu identificar uma pequena variação espacial das chuvas com valores máximos e mínimos de 1112 e $1000 \mathrm{~mm} / \mathrm{ano}$, respectivamente. Estes valores coincidem com àqueles apresentados por Andrade Júnior et al. (2004), que identificaram para a região sul do estado do Piauí uma precipitação média anual de 1000 a $1200 \mathrm{~mm}$. 


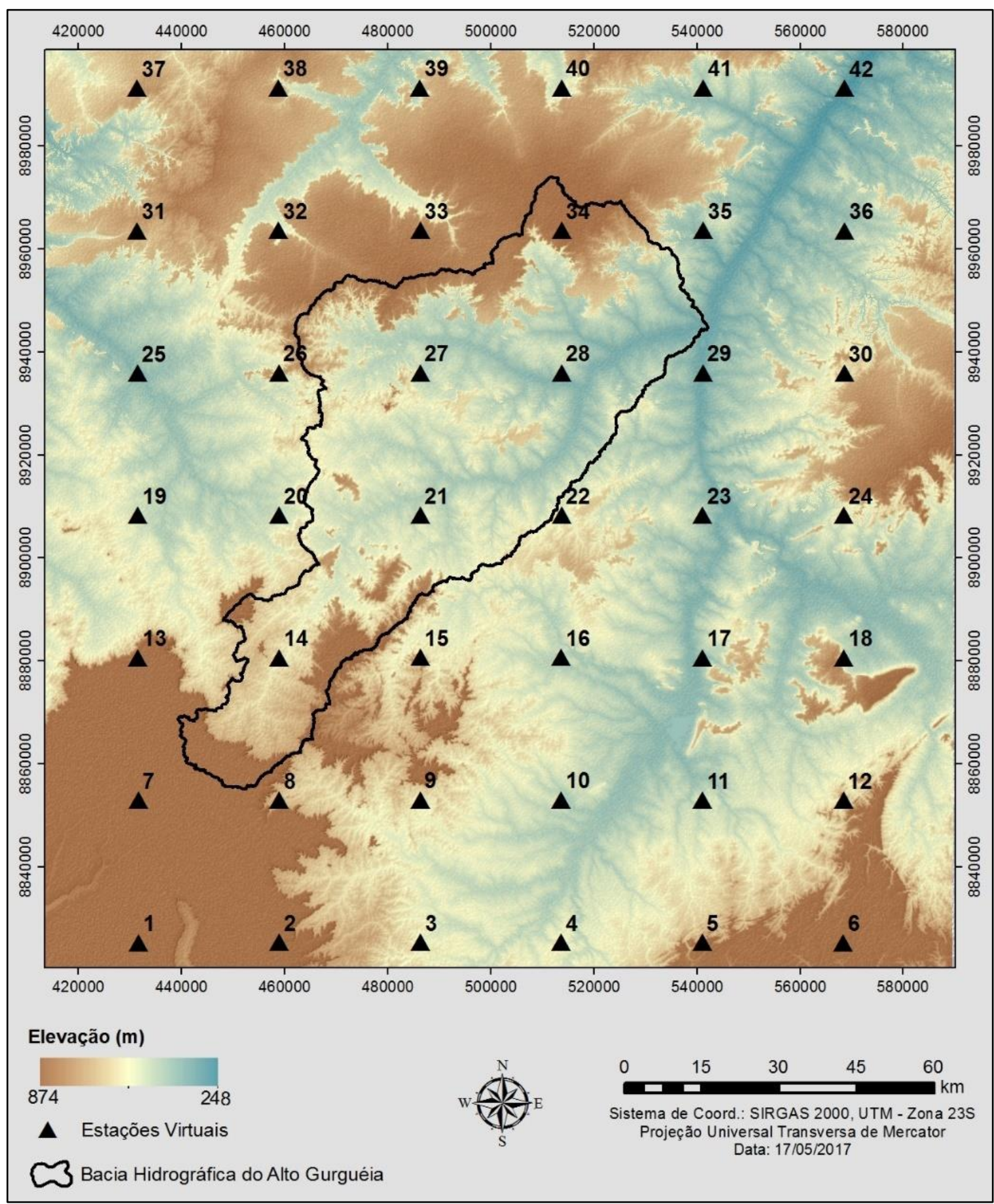

Figura 3 - Localização das 42 estações virtuais de análise climática da bacia hidrográfica do Alto Gurguéia. Fonte: elaborado pelos autores.

A espacialização do fator R apresentada na Figura 5 evidencia que a BHAG apresenta altos índices de erosividade, com valor médio de $6.297 \mathrm{Mj} \cdot \mathrm{mm} \cdot \mathrm{ha}^{-1} \cdot \mathrm{h}^{-1} \cdot \mathrm{ano}^{-1}$ e pequenas variações ao longo de sua extensão com leve tendência de aumento na direção sudoeste, o que demonstra homogeneidade na distribuição espacial e temporal das precipitações na região. 


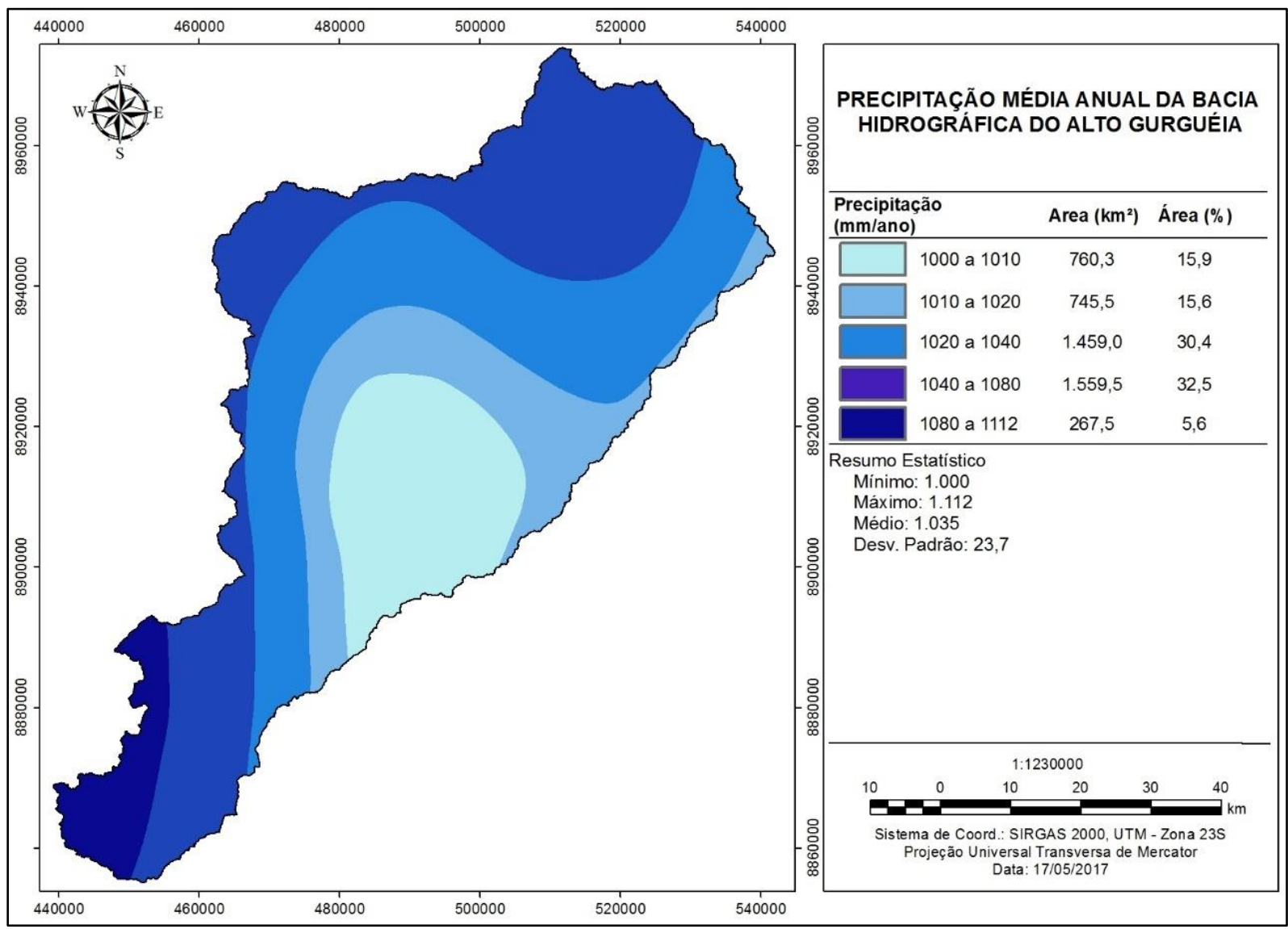

Figura 4 - Precipitação média anual (mm) da bacia hidrográfica do Alto Gurguéia, Piauí, Brasil.

Fonte: elaborado pelos autores.

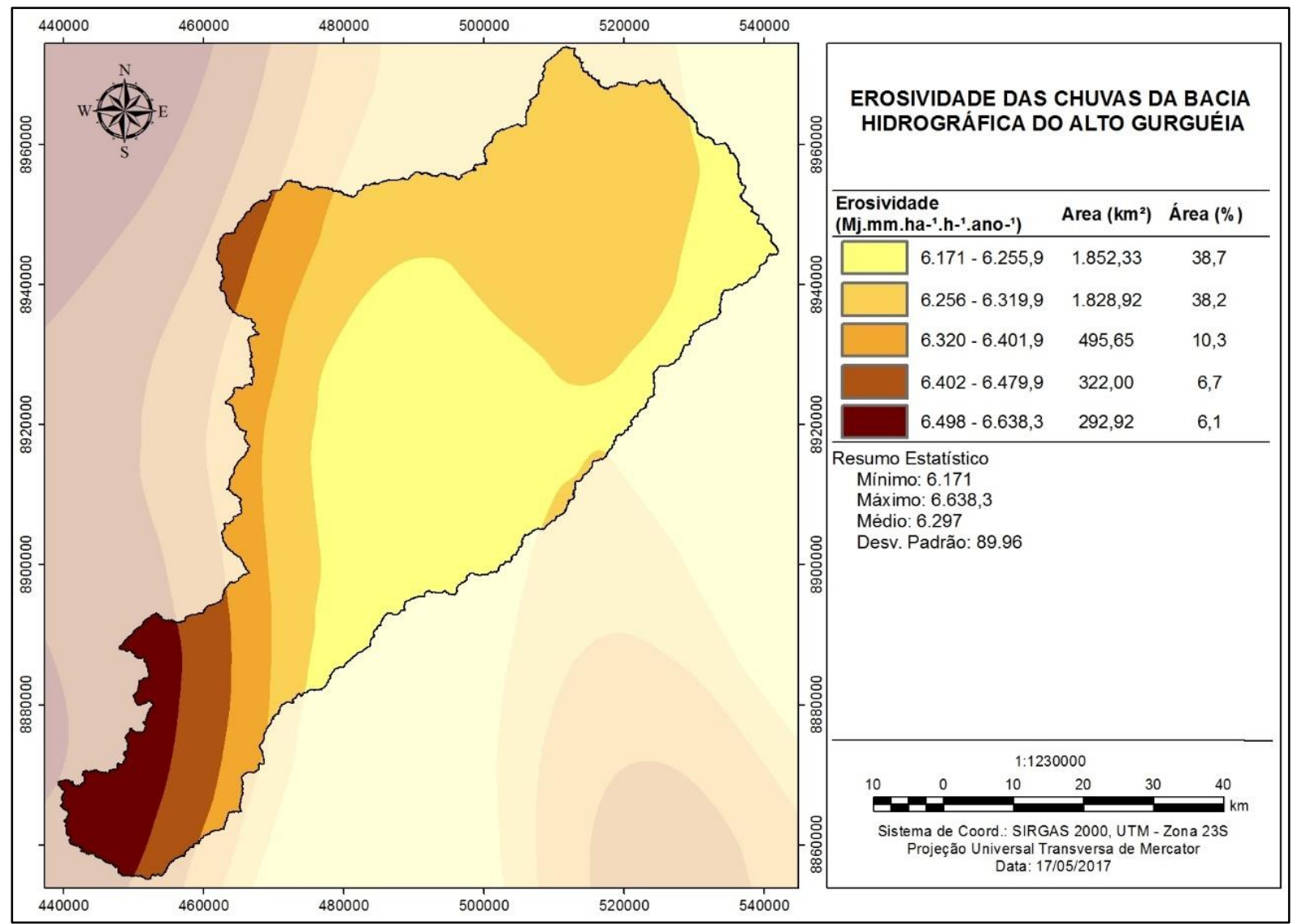

Figura 5 - Erosividade das chuvas na Bacia Hidrográfica do Alto Gurguéia, Piauí Brasil.

Fonte: elaborado pelos autores. 
Os valores do fator R identificados são superiores aos apresentados por Farinasso et al. (2006) em estudo realizado na bacia hidrográfica do Alto Parnaíba (3.500 a $\left.5.000 \mathrm{Mj} \cdot \mathrm{mm} \cdot \mathrm{ha}^{-1} \cdot \mathrm{h}^{-1} \cdot \mathrm{ano}^{-1}\right)$ na qual a BHAG está inserida. Na ocasião, os autores utilizaram registros de 52 estações terrestres, operadas pela Agência Nacional de Águas, com espaçamentos irregular e séries históricas variáveis (entre 20 e 30 anos). Acredita-se que a diferença no intervalo temporal dos dados e a distribuição irregular das estações possa explicar as diferenças encontradas.

Amorim e Aquino (2015) em trabalho realizado nos municípios de Castelo do Piauí e Juazeiro do Piauí, identificaram índices de erosão médio anual variando entre 6.460 e $7.600 \mathrm{Mj} \cdot \mathrm{mm}_{\mathrm{h}} \mathrm{ha}^{-1} \mathrm{~h}^{-}$ ${ }^{1}$. ano $^{-1}$. Tais valores se aproximam dos identificados para esta mesma região utilizando o banco de dados apresentado neste estudo (5.475 a $7.370 \mathrm{Mj} \cdot \mathrm{mm} \cdot \mathrm{ha}^{-1} \cdot \mathrm{h}^{-1} \cdot \mathrm{ano}^{-1}$ ), em comparativo realizado para fins de análise de consistência dos resultados. Mais uma vez as diferenças podem ser explicadas pelo recorte temporal, visto que os dados de precipitação estimados por satélite que compõem o banco de dados deste estudo foram registrados no período de 1998 a 2016, enquanto a série histórica de 23 anos utilizada pelos autores correspondem ao período de 1962 a 1985.

Passos et al. (2014) também avaliaram a eficiência dos dados de precipitação estimados por satélite (TRMM) ao calcularem o fator R para obtenção da estimativa de perda de solo da bacia do Alto São Francisco. Segundo os autores os dados de precipitação TRMM se mostraram uma alternativa viável aos dados convencionais, visto que estes são disponibilizados de forma contínua desde 1998 até o presente.

\subsection{Fator $\mathbf{K}$}

$\mathrm{Na}$ bacia hidrográfica do Alto Gurguéia foram identificadas a ocorrência de 13 classes de solos, tendo como referência a base de dados do (IBGE, 2015). A distribuição espacial dessas classes é apresentada Figura 6, onde observa-se a predominância dos Latossolos Amarelo Distróficos (39,3\% da área total), seguindo dos Neossolos Litólicos Distróficos (24,6\%), Neossolos Quartizarênicos (12,2\%) e Luvissolos Crômico Órtico (11,4\%). As demais classes juntas cobrem 12,5\% da área da bacia.

As classes de solos da BHAG, seguidos dos seus respectivos valores de erodibilidade são apresentados na Tabela 3. Estes dados foram inseridos na tabela de atributos das classes de solos para obtenção do mapa da distribuição espacial de K no formato matricial (Figura 7). 


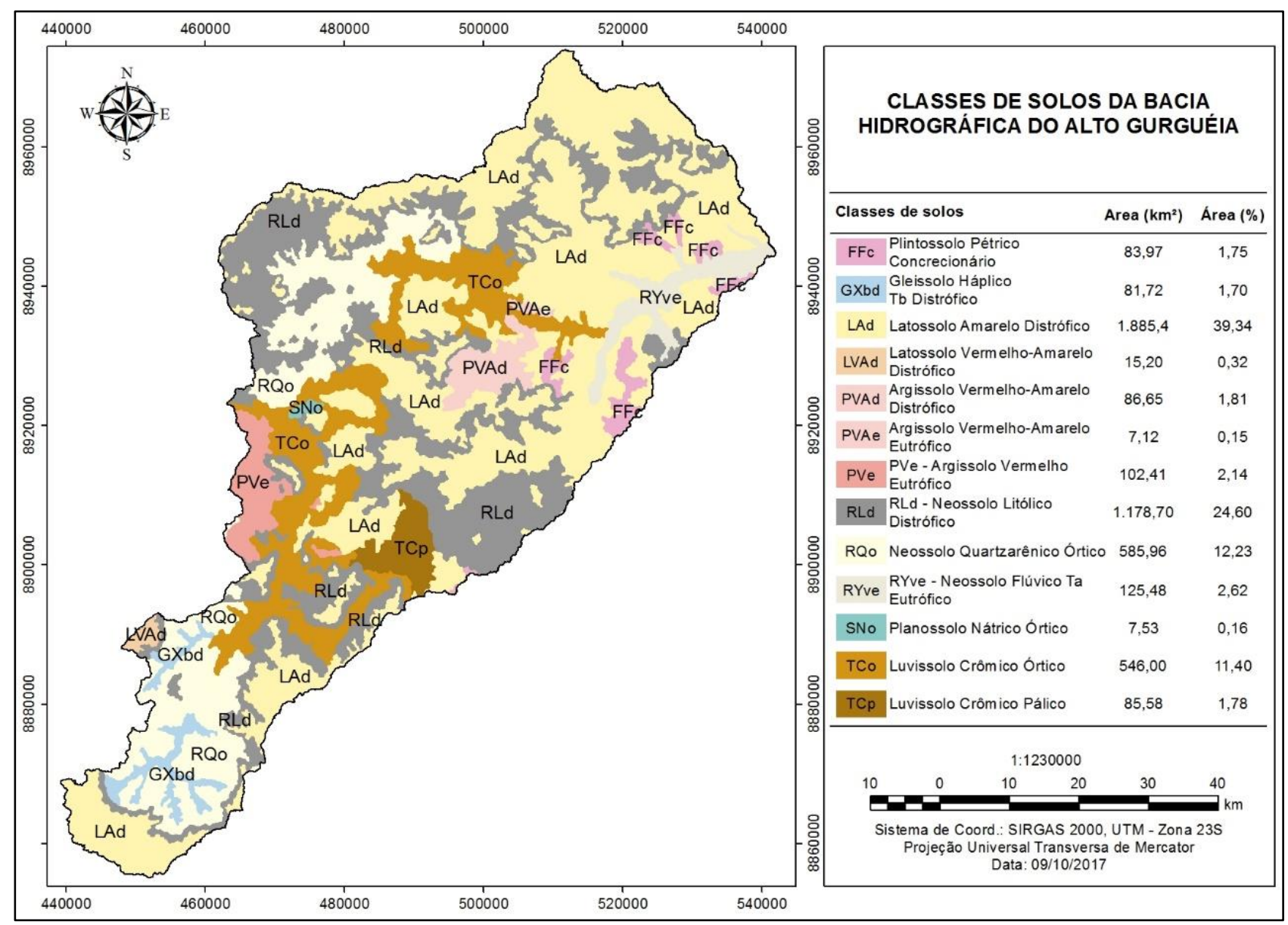

Figura 6 - Classes de solos da bacia hidrográfica do Alto Gurguéia.

Fonte: elaborado pelos autores. Base cartográfica: IBGE (2015).

Dentre as principais classes de solos identificadas com baixa e muito baixa susceptibilidade à erosão destaca-se: os Gleissolos, encontrados especialmente nas áreas de cabeceiras, geralmente associado ao ambiente úmido das veredas; os Argissolos Vermelhos Eutróficos, limitado a uma pequena porção na região centro-leste da bacia, caracterizada por um relevo suave ondulado; e os Neossolos Quartizarênicos Órticos encontrados ao sul e leste da bacia situados, predominantemente, em áreas de relevo suave ondulado defronte as bordas dos planaltos e chapadas. Por outro lado, como solos mais suscetíveis à erosão $(\mathrm{k}>0,043)$ destacam-se os argissolos vermelho-amarelo localizados na porção nordeste da bacia, e os Plintossolos localizados na planície de inundação nas proximidades do exutório. Já entre os solos com erosividade moderada destacam-se, devido sua extensão espacial: os latossolos amarelo distróficos, que se distribuem por toda a bacia, notadamente nas áreas de relevo plano dos planaltos e chapadas e ao longo do vale; os Neossolos Litólicos, especialmente encontrado no sopé das escarpas erodidas dos planaltos, chapadas e superfícies residuais; os luvissolos crômicos que ocorrem na porção central da bacia. 
Tabela 1 - Associação de solos da bacia hidrográfica do Alto Gurguéia e seus respectivos valores de erodibilidade.

\begin{tabular}{llcc}
\hline \multirow{2}{*}{ Símbolo } & \multicolumn{1}{c}{ Tipo de solo } & $\begin{array}{c}\text { K } \\
\text { (t.ha.h/ha.MJ.mm) }\end{array}$ & Classes de K \\
\hline PVAd & Argissolo Vermelho-Amarelo Distrófico & 0,0592 & Muito Alta \\
PVAe & Argissolo Vermelho-Amarelo Eutrófico & 0,0577 & Alta \\
FFc & Plintossolo Pétrico Concrecionário & 0,0438 & Alta \\
TCo & Luvissolo Crômico Órtico & 0,0384 & Moderada \\
TCp & Luvissolo Crômico Pálico & 0,0384 & Moderada \\
RYve & Neossolo Flúvico Ta Eutrófico & 0,0366 & Moderada \\
RLd & Neossolo Litólico Distrófico & 0,0362 & Moderada \\
LAd & Latossolo Amarelo Distrófico & 0,0277 & Moderada \\
GXbd & Gleissolo Háplico Tb Distrófico & 0,0274 & Baixa \\
LVAd & Latossolo Vermelho-Amarelo Distrófico & 0,0264 & Muito Baixa \\
RQo & Neossolo Quartzarênico Órtico & 0,0227 & Muito Baixa \\
SNo & Planossolo Nátrico Órtico & 0,0219 & Muito Baixa \\
PVe & Argissolo Vermelho Eutrófico & 0,0197 & Muito Baixa \\
\hline
\end{tabular}

Fonte: dados da pesquisa.

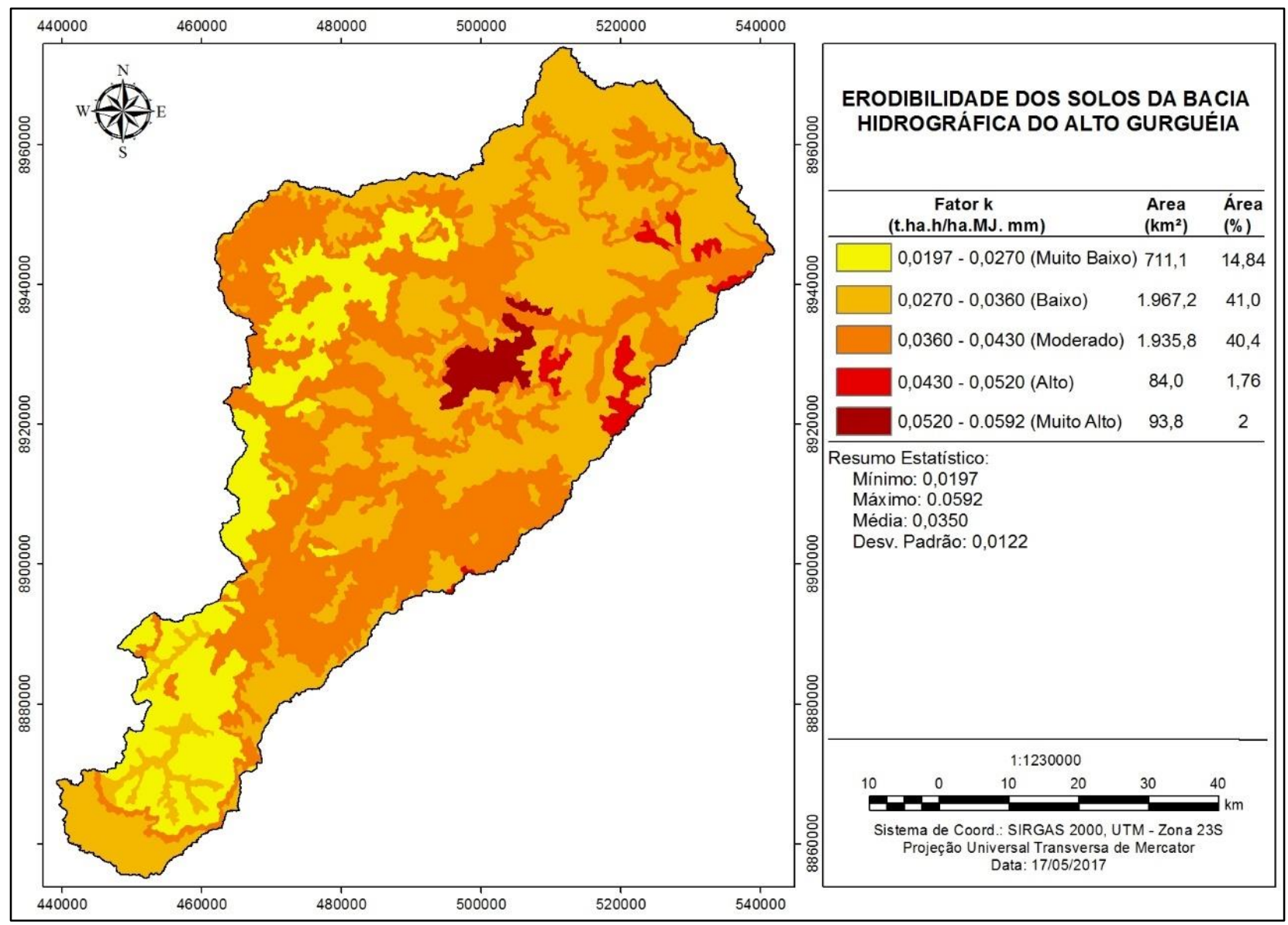

Figura 7 - Erodibilidade dos solos da bacia hidrográfica do Alto Gurguéia.

Fonte: elaborado pelos autores. Base cartográfica: IBGE (2015).

\subsection{Fator LS}

O fator LS da BHAG obtido por meio da ferramenta LS-TOOL com uso dos dados AW3D é apresentado na Figura 8, onde é possível observar uma forte associação espacial deste fator com a declividade, conforme descrito por Galdino (2015), haja vista que as áreas que apresentaram fator LS 
mais elevados correspondem às áreas de escarpas erodidas dos planaltos, chapadas e morros residuais. Assim sendo, o fator LS da BHAG, variou entre 0.009 e 82,5 (adimensional) e apresentou uma média e desvio padrão de 1,73 e 4,16 , respectivamente.

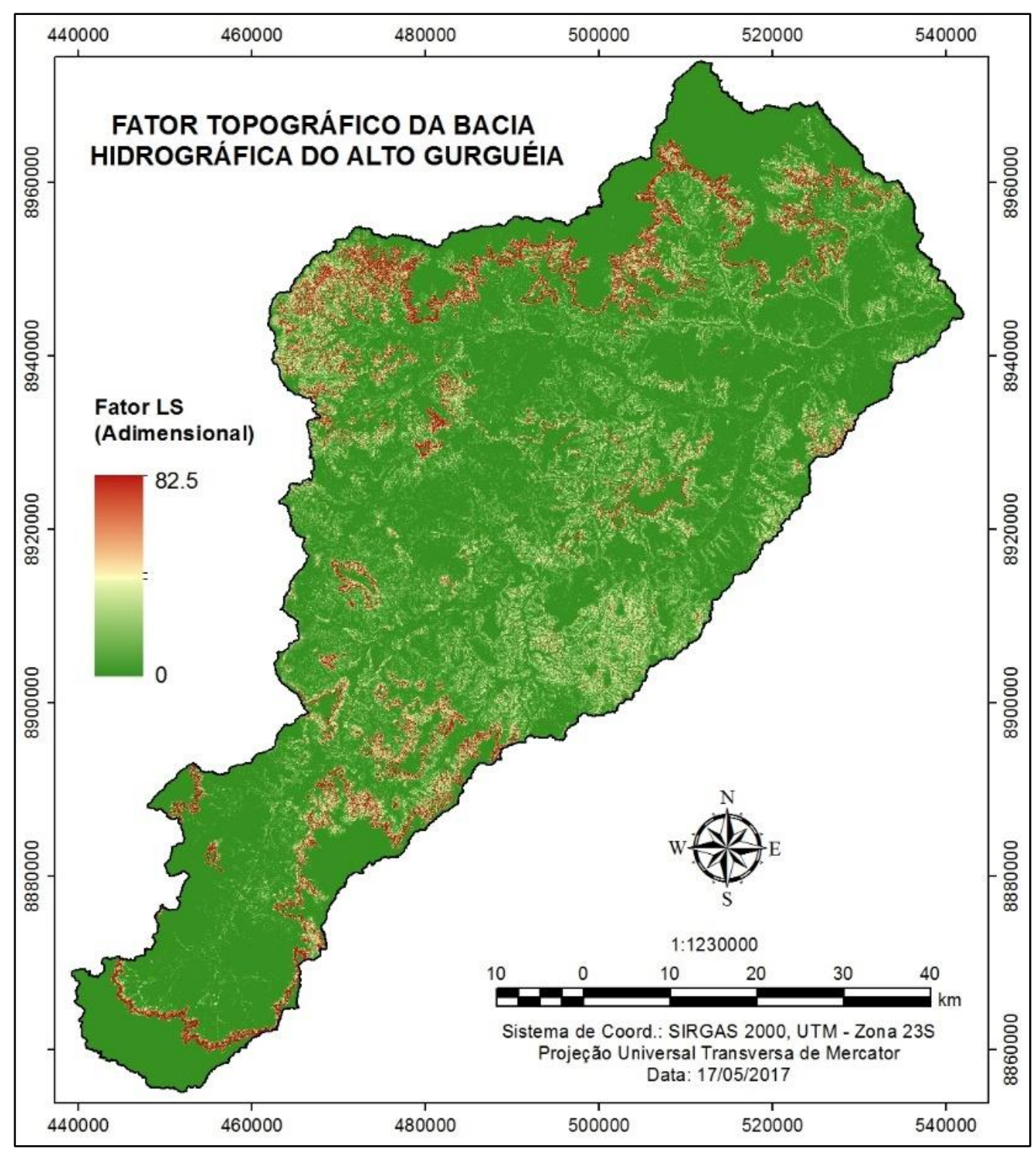

Figura 8 - Fator topográfico da bacia hidrográfica do Alto Gurguéia.

Fonte: elaborado pelos autores.

O fator LS é bastante sensível ao algoritmo e a base de dados utilizada. Neste caso, quanto maior a resolução espacial e precisão vertical do MDE mais acurado será o resultado. Diante disso, torna-se inviável a comparação dos resultados ora apresentados com os já dispostos na literatura como o trabalho desenvolvido por Farinasso et al. (2006) na bacia hidrográfica do Alto Parnaíba, da qual a BHAG é integrante, onde os autores obtiveram o MDE a partir da interpolação do dados altimétricos da Base Cartográfica Integrada ao Milionésimo do IBGE que, em função da escala original dos dados, resulta em um MDE com escala espacial bastante inferior àqueles derivados de sensoriamento remoto, sobretudo ao utilizado neste trabalho. 
Galdino (2015), em trabalho desenvolvido na bacia do Alto Paraguai, utilizou o MDE derivado de sensoriamento remoto (dados Shuttle Radar Topography Mission) e o software LSTOOL para obtenção do fator LS, que apresentou uma variação de 0,05 a 156,46 (adimensional), demonstrando a eficiência desta ferramenta na estimativa deste parâmetro em grandes áreas.

Em estudos de pequenas áreas, como microbacias hidrográficas ou uma determinada encosta, a utilização de MDE derivado de sensoriamento remoto orbital fica impossibilitada devido a escala de trabalho demandar o uso de dados de elevação de alta resolução, não disponível de forma gratuita. Entretanto, a obtenção de dados altimétricos com o uso de veículos aéreos não tripulados (VANT) tem possibilitado a obtenção de MDE mais precisos e a custos mais baixos, que pode vir a favorecer obtenção do fator LS em pequenas áreas.

\subsection{Potencial natural de erosão dos solos}

O mapa do PNE da BHAG apresentado na Figura 9 é resultado do produto dos mapas dos parâmetros físicos da EUPS (fator R, K e LS) processado em ambiente SIG com uso da calculadora raster. Na definição das classes do PNE adotou-se a proposta apresentada por Silva; Alvares e Watanabe (2011) no estudo sobre potencial natural de erosão dos solos do Brasil.

A BHAG apresenta um PNE médio de 373,4 t.ha ${ }^{-1} \cdot$ ano $^{-1}$. No entanto, conforme apresentado na Figura 9, o menor potencial erosivo (PNE $\leq 200$ t.ha-1.ano-1) estão associadas às áreas e relevo plano e se estendem por 64,9\% da área da bacia, enquanto que o maior potencial erosivo (PNE > 1.600 t.ha ${ }^{-1} \cdot$ ano $^{-1}$ ) ocorre nas áreas de alta declividade, geralmente associada às escapas erodidas das bordas dos planaltos e ocupam 6,8\% da área da bacia. As áreas de baixo, moderado e alto PNE ocupam, respectivamente, 15,1, 7,7 e 5,5\% da área total da bacia.

De modo geral, a BHAG apresenta baixo PNE se comparada com estudo realizado na bacia hidrográfica do rio Passa Cinco, São Paulo, onde Carvalho et al., (2010) identificaram que 58,79\% dessa bacia apresenta um PNE superior 1.500 t.ha ${ }^{-1} \cdot$ ano $^{-1}$, enquanto que apenas 9,36\% da bacia apresenta um PNE considerado baixo (PNE $<500$ t.ha ${ }^{-1}$.ano ${ }^{-1}$ ). Segundo os autores, as variações observadas nos valores do PNE estão associadas à declividade e a susceptibilidade dos solos à erosão.

Bhering et al. (2014) utilizaram o PNE junto com outros parâmetros na elaboração do Zoneamento Agroecológico do Estado de Mato Grosso. Segundo os autores as áreas com maior PNE (PNE > 200 t.ha ${ }^{-1} \cdot$ ano $^{-1}$ ) estão fortemente associadas a áreas de declividade elevada e foram recomendadas para conservação dos recursos naturais ou recuperação ambiental. 


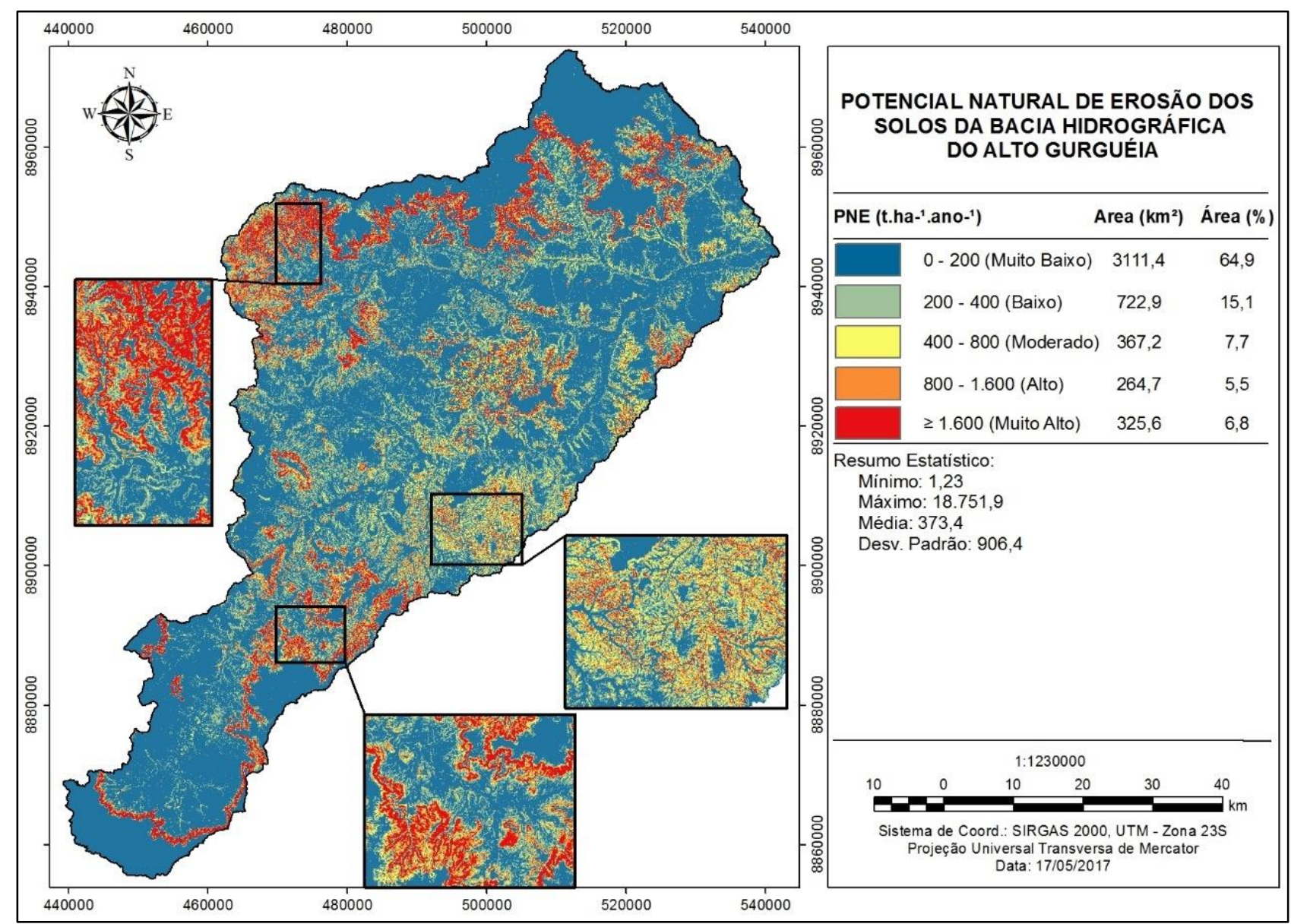

Figura 9 - Potencial Natural de Erosão dos solos da bacia hidrográfica do Alto Gurguéia.

Fonte: elaborado pelos autores.

A influência de cada parâmetro em relação ao PNE foi analisada a partir de uma matriz de correlação linear com uso da ferramenta Band Collection Statistics da extensão Spatial Analyst Tools do ArcGis. No caso de um conjunto de camadas raster, a matriz de correlação apresenta os valores de célula de uma camada raster em função dos valores de célula de outra camada. A correlação entre duas camadas é, portando, uma medida de dependência entre as camadas. A correlação varia de +1 a -1, onde uma correlação positiva indica uma relação direta entre duas camadas, enquanto que uma correlação negativa significa que uma variável muda inversamente em relação a outra. Uma correlação com valor zero significa que duas camadas são independentes (ESRI, 2017).

A análise de correlação entre o PNE e os fatores R, K, LS, apresentada na Tabela 2 demostra que a distribuição espacial do PNE na bacia hidrográfica do Alto Gurguéia é mais fortemente correlacionada com fator topográfico (LS) $\left(\mathrm{r}^{2}=0,987\right)$. A forte influência da topografia na espacialização das classes de PNE também foi identificada por Silva (2008) em trabalho semelhante realizada no município de Sorocaba, onde o PNE e fator LS apresentaram uma correlação de 0,96. 
Tabela 2 - Matriz de correlação $\left(r^{2}\right)$ entre o PNE e os fatores R, K e LS obtidos para a bacia hidrográfica do Alto Gurguéia.

\begin{tabular}{ccccc}
\hline & PNE & R & K & LS \\
\hline PNE & 1 & $-0,003$ & 0,234 & 0,987 \\
R & $-0,003$ & 1 & $-0,321$ & 0,003 \\
K & 0,234 & $-0,321$ & 1 & 0,172 \\
LS & 0,987 & 0,003 & 0,172 & 1 \\
\hline \multicolumn{5}{c}{ Fonte: dados da pesquisa. }
\end{tabular}

Fonte: dados da pesquisa.

A correlação nula das elevadas taxas de erosividade (6.951 a $\left.7.366 \mathrm{Mj} \cdot \mathrm{mm} \cdot \mathrm{ha}^{-1} \cdot \mathrm{h}^{-1} \cdot \mathrm{ano}^{-1}\right)$ da BHAG na estimativa do PNE deve-se a sua pequena variabilidade espacial ao logo da bacia, conforme demonstrado na Figura 5, embora se reconheça que tais valores são potencialmente influenciadores de processos erosivos. A erodibilidade dos solos apresentou fraca correlação positiva com PNE $\left(\mathrm{r}^{2}=\right.$ 0,234), provavelmente influenciado pela escala do mapeamento pedológico utilizado.

\section{CONCLUSÕES}

O conhecimento acerca dos condicionantes e processos erosivos constitui importante instrumento de gestão ambiental em bacias hidrográfica. Diante disso, o presente trabalhou procurou identificar o potencial natural de erosão dos solos da bacia hidrográfica do Alto Gurguéia a partir dos parâmetros físicos da EUPS (erosividade das chuvas, erodibilidade dos solos e fator topográfico) utilizando técnicas de geoprocessamento e produtos derivados de sensoriamento remoto.

Conclui-se que a BHAG apresenta baixo potencial natural de erosão, visto que em $64,9 \%$ da bacia os valores do PNE ficam abaixo dos 200 t.ha $^{-1}$. ano $^{-1}$, contudo, nas áreas declivosas esses valores podem ultrapassam os 1.600 t.ha $^{-1}$. ano $^{-1}$ demonstrando a forte correlação do fator topográfico com a estimativa do PNE em detrimento aos demais parâmetros. A correlação nula das elevadas taxas de erosividade das chuvas verificadas na bacia $\left(\mathrm{R}_{\text {média }}=6.297 \mathrm{MJ} \cdot \mathrm{mm} \cdot \mathrm{ha}^{-1} \cdot \mathrm{h}^{-1}\right)$ é atribuída a sua pequena variabilidade espacial na área da bacia.

A identificação do fator topográfico como principal parâmetro influenciador dos processos erosivos frente à condição de excessiva erosividade das chuvas na BHAG evidencia a alto risco de erosão a que estão submetidas as áreas da bacia que apresentam declividade acentuada, condição que demanda a adoção de planejamento ambiental com vista a disciplinar o uso e ocupação compatibilizado as categorias de uso às condições ambientais da bacia. 


\section{REFERÊNCIAS}

ACCIOLY, L. J. O.; ARAÚJO, A. M.; SILVA, A. B.; LOPES, H. L.; SILVA, E. A. Estimatica do Potencial Natural de Erosão das Terras da Bacia do Rio Ipojuca-PE. In: XVIII REUNIÃO BRASILEIRA DE MANEJO E CONSERVAÇÃO DO SOLO E DA ÁGUA, Teresina, 2010. Anais... Teresina: Embrapa Meio Norte, 2010. Disponível em: < https://ainfo.cnptia.embrapa.br/digital/ bitstream/item/90248/1/495.pdf > Acesso em: 09 out. 2017.

AMORIM, F.; AQUINO, C. M. S. Erosividade das chuvas (R) nos municípios de Castelo do Piauí e Juazeiro do Piauí, no estado do Piauí (Brasil). Geoambiente On-Line. v. 2, n. 13, 2015. p. 57-72. Disponível em: 〈https://revistas.ufg.br/geoambiente/article/view/37358>. Acesso em: 4 jul. 2017.

ANDRADE JUNIOR, A. S.; BASTOS, E. A.; SILVA, C. O.; GOMES, A. A. N.; FIGUEREDO JÚNIOR, L. G. M. Atlas Climatológico do Estado do Piauí. Teresina: Embrapa Meio Norte, 2004. 151 p. (Documentos, 101). Disponível em: <http://www.cpamn.embrapa.br/publicacoes/ documentos/2004/doc_101.pdf>. Acesso em: 3 ago. 2015.

ANDRADE JUNIOR, A. S.; BASTOS, E. A.; BARROS, A. H. C.; SILVA, C. O.; GOMES, A. A. N. Classificação climática e regionalização do semi-árido do Estado do Piauí sob cenários pluviométricos distintos. Revista Ciência Agronômica, v. 36, n. 2, 2005. p. 143-151.

ARAÚJO, F. S.; SALVIANO, A. A. C.; HOLANDA NETO, M. R. Estimativa da erodibilidade de latossolos do Piauí. Scientia Plena, v. 7, n. 10, 2011. p. 2839-2845. Disponível em: <https://www.scientiaplena.org.br/sp/article/viewFile/358/206>. Acesso em: 4 jul. 2017.

BERTONI, J.; LOMBARDI NETO, F. Conservação do solo. 9. ed. São Paulo: Ícone, 2014. 355 p.

BHERING, S. B.; CHAGAS, C. S.; CARVALHO JÚNIOR, W.; PEREIRA, N. R.; AMARAL, F. C. S.; ZARONI, M. J.; GONÇALVES, A. O. Geotecnologias aplicadas ao Zoneamento Agroecológico do Estado do Mato Grosso do Sul. Sociedade \& Natureza. v. 26, n. 1, p. 171-187, 2014. Disponível em: 〈http://www.seer.ufu.br/index.php/sociedadenatureza/article/view/17817/pdf_77>. Acesso em: 4 jul. 2017.

CARVAlHO, E. M.; PINTO, S. A. F.; SEPE, P. M.; ROSSETI, L. A. F. G. Utilização do geoprocessamento para avaliação de riscos de erosão do solo em uma bacia hidrográfica: estudo de caso da bacia do rio Passa Cinco/SP. In: SIMPÓSIO BRASILEIRO DE CIÊNCIAS GEODÉSICAS E TECNOLOGIAS DA GEOINFORMAÇÃO, 3, 2010, Recife. Anais... Recife: UFPE, 2010. p. 18. Disponível em: <https://www.ufpe.br/cgtg/SIMGEOIII/IIISIMGEO_CD/artigos/.../ SIG/A_101.pdf>. Acesso em: 3 abr. 2016.

CREPANI, E. O Núcleo de Desertificação de Gilbués observado pelo Sensoriamento Remoto e pelo Geoprocessamento. In: XIV SIMPÓSIO BRASILEIRO DE SENSORIAMENTO REMOTO, 2009, Natal. Anais.... Natal: INPE, 2009. p. 5185-5192. 
DEMARCHI, J. C. Geotecnologias aplicadas a estimativa de perdas de solo por erosão hídrica na sub-bacia do Ribeirão das Perobas, municipio de Santa Cruz do Rio Pardo, São Paulo. 2012. 167 f. Dissetação (Mestrado em Agrononia) - Universidade Esdatual Paulista "Júlio de Mesquita Filho", Botucatu, 2012. Disponível em : <https://repositorio.unesp.br/bitstream/handle/11449/90559/ demarchi_jc_me_botfca.pdf?sequence=1\&isAllowed=y >. Acesso em: 09 out. 2017.

DENARDIN, J. E. Erodibilidade do solo estimada por meio de parâmetros fisicos e químicos. 1990. 114 f. Tese (Doutorado em Agronomia) - Escola Superior de Agriculura Luiz de Queiroz, Universidade de São Paulo, 1990.

ENVIRONMENTAL SYSTEMS RESEARCH INSTITUTE. How Band Collection Statistics works. Disponível em: <http://pro.arcgis.com/en/pro-app/tool-reference/spatial-analyst/how-bandcollection-statistics-works.htm>. Acesso em: 10 maio 2017.

FARINASSO, M.; CARVALHO JÚNIOR, O. A.; GUIMARÃES, R. F.; GOMES, R. A. T.; RAMOS, V. M. Avaliação qualitativa do potencial de erosão laminar em grandes áreas por meio da EUPS Equação Universal de Perdas de Solo - utilizando novas tecnologias em SIG para os cálculos dos seus fatores na região do Alto Parnaíba - PI-MA. Revista Brasileira de Geomorfologia, v. 2, 2006. p. 73-85. Disponível em: <http://www.ugb.org.br/home/artigos/SEPARATAS_RBG_Ano_7_n_2_ 2006/RBG_Ano_7_n_2_2006_73_85.pdf>. Acesso em: 4 jul. 2017.

FERREIRA, R. V.; DANTAS, M. E. Relevo. In: PFALTZGRAFF, P. A. S.; TORRES, F. M. T.; BRADÃO, R. L. (Org.). Geodiversidade do estado do Piauí. Recife: CPRM, 2010. p. 45-64. Disponível em: <http://www.cprm.gov.br/publique/media/Geodiversidade_PI.pdf >. Acesso em: 10 set. 2015.

GALDINO, S. Distribuição espacial do fator topográfico da Rusle na Bacia do Alto Paraguai. Campinas, SP: Embrapa Monitorameto por Satélite, 2015. (Boletim de Pesquisa e Desenvolvimento, 30). Disponível em: <http://ainfo.cnptia.embrapa.br/digital/bitstream/item/138339/1/4669.pdf>. Acesso em: 4 jul. 2017. 23 p.

GONÇALVES, J. H. (Coord.). Mapa geológico do estado do Piauí. 2. ed. Teresina: CPRM, 2006. Disponível em: <http://www.cprm.gov.br/publique/media/mapa_piaui.pdf>. Acesso em: 28 jun. 2016.

GUERRA, A. J. T. O início do processo erosivo. In: GUERRA, A. J. T.; SILVA, A. S.; BOTELHO, R. G. M. (Org.). Erosão e conservação dos solos: conceitos, temas e aplicações. 2. ed. Rio de Janeiro: Oficina de Texto, 2005a. p. 17-55.

GUERRA, A. J. T. Processos erosivos nas encostas. In: GUERRA, A. J. T.; CUNHA, S. B. (Org.). Geomorfologia: uma atualização de bases e conceitos. 6. ed. Rio de Janeiro: Bertrand Brasil, 2005b. p. 149-210.

GUIMARÃES, R. Z.; LINGNAU, C.; RIZZI, N. E.; SCHEICHI, R. G.; BIANCHI, R. C. Espacialização da perda de solo por eroão laminar na microbacia do rio Campinas, Joinville SC. RA'E GA - O Espaço Geográfico em Análise. v. 23, 2011. p. 534-554. Disponível em: <revistas.ufpr.br/raega/article/download/24920/16719>. Acesso em: 4 jul. 2017. 
INSTITUTO BRASILEIRO DE GEOGRAFIA E ESTATÍSTICA. Solos. Folha SC-23. Rio de Janeiro: IBGE , 2015b. <http://downloads.ibge.gov.br/downloads_geociencias.htm>. Acesso em: 14 jun. 2016.

JACOMINE, P. K. T. Levantamento exploratório - reconhecimento de solos do Estado do Piauí. Rio de Janeiro: EMBRAPA - SNLCS/SUDENE, 1986. (Boletim de pesquisa, 26).

JAPAN AEROSPACE EXPLORATION AGENCY. ALOS Global Digital Surface Model "ALOS World 3D - 30m" (AW3D30). Disponível em: <http://www.eorc.jaxa.jp/ALOS/en/aw3d30/>. Acesso em: 1 jan. 2016.

LEPSCH, I. F. Formação e conservação dos solos. 2. ed. São Paulo: Oficina de Texto, 2010.

LIMA, E. A. A.; BRADÃO, R. L. Geologia. In: PFALTZGRAFF, P. A. S.; TORRES, F. M. T.; BRADÃO, R. L. (Org.). Geodiversidade do estado do Piauí. Recife: CPRM, 2010. p. 15-24. Disponível em: 〈http://www.cprm.gov.br/publique/media/Geodiversidade_PI.pdf>. Acesso em: 10 set. 2015.

LOMBARDI NETO, F.; MOLDENHAUER, W. C. Erosividade da chuva: sua distribuicao e relacao com as perdas de solo em Campinas (SP). Bragantia, v. 51, n. 2, p. 189-196, 1992. Disponível em: <www.scielo.br/pdf/brag/v51n2/09.pdf $>$. Acesso em: 15 mar. 2017.

OLIVEIRA, J. A.; DOMINGUEZ, J. M. L.; NEARING, M. A.; OLIVEIRA, P. T. S. A GIS-Based procedure for automatically calculation soil loss fron the universal soil loss equation: GISus-M. American Society of Agricultural and Biological Engineers. v. 31, n. 6, 2015. p. 907-917. Disponível em: <http://elibrary.asabe.org/abstract.asp?aid=46531\&t=3\&dabs=Y\&redir=\&redirTy pe=>. Acesso em: 4 jul. 2017.

PASSOS, J. S. A.; BELTRÃO, J. A.; SANTOS, C. A. G.; SILVA, R. M. Estimativa de perdas de solo na bacia do Alto São Francisco utilizando precipitação estimada por satélite. In: ENCONTRO NACIONAL DE ENGENHARIA DE SEDIMENTOS, 11, 2014, João Pessoa. Anais... João Pessoa: ABRH, 2014. Disponível em: <https://www.abrh.org.br/SGCv3/UserFiles/Sumarios/aba910b 1ab9dc540705d26d4436290ba_50d568377cde79af908d20f59b7c018f.pdf>. Acesso em: 04 jul. 2017.

SALES, M. C. L. Degradação ambiental em gilbués, Piauí. Mercator, n. 4, p. 115-124, 2003. Disponível em: 〈http://www.mercator.ufc.br/index.php/mercator/article/viewFile/156/123>. Acesso em: 10 ago. 2015.

SALOMÃO, F. X. T. Controle e prevenção de processos erosivos. In: GUERRA, A. J. T.; SILVA, A. S.; BOTELHO, R. G. M. (Org.). Erosão e conservação dos solos: conceitos, temas e aplicações. 2. ed. Rio de Janeiro: Bertrand Brasil, 2005. p. 229-267.

SILVA, A. M. DA. Potencial natural de erosão no município de Sorocaba. Rev. Int. de Desastres Naturales, Accidentes e Infraestructura Civil, v. 8, n. 1, 2008. p. 5-14. Disponível em: <https://academic.uprm.edu/laccei/index.php/RIDNAIC/article/view/146/142>. Acesso em: 10 maio 2017. 
TAKAKU, J.; TADONO, T.; TSUTSUI, K. Generation of High Resolution Global DSM from ALOS PRISM. ISPRS - International Archives of the Photogrammetry, Remote Sensing and Spatial Information Sciences, v. XL-4, n. 4, p. 243-248, 2014. Disponível em: <http://www.int-archphotogramm-remote-sens-spatial-inf-sci.net/XL-4/243/2014/>. Acesso em: 04 jul. 2017.

TROPICAL RAINFALL MEASURING MISSION. TRMM (TMPA/3B43) Rainfall Estimate L3 1 month 0.25 degree $x \mathbf{0 . 2 5}$ degree V7 . Greenbelt, MD: Goddard Earth Sciences Data and Information Services Center (GES DISC). Disponível em: <https://disc.gsfc.nasa.gov/datacollection/ TRMM_3B43_7.html>.Acesso em: 28 abr. 2017., 2011

WISCHMEIER, W. H.; SMITH, D. D. Prediciting rainfall erosion losses: a guide to conservation planning. Washington: USDA, 1978. 58 p. Disponível em: <https://naldc.nal.usda.gov/download/ CAT79706928/PDF>. Acesso em 09 out. 2017.

YAMAMOTO, J. K.; LANDIM, P. M. B. Geoestatística: conceitos e aplicações. São Paulo: Oficina de Texto, 2013. 215 p.

ZHANG, H.; YANG, Q.; LI, R.; LIU, Q.; MOORE, D.; HE, P.; RITSEMA, C. J.; GEISSEN, V. Extension of a GIS procedure for calculating the RUSLE equation LS factor. Computers and Geosciences. v. 52, 2013.p. 177-188. Disponível em: <http://linkinghub.elsevier.com/retrieve /pii/S0098300412003378>. Acesso em: 04 jul. 2017. 